\title{
Protein phosphatase PP2C in the flagellum of Leishmania major: cloning and characterization
}

\section{cambridge.org/pao}

\section{Research Article}

Cite this article: Escalona-Montaño AR, Pérez Montfort R, Cabrera N, Mondragón-Flores R, Vélez-Ramírez DE, Gómez-Sandoval JN, Gutiérrez-Kobeh L, Becker I, Aguirre-García MM (2017). Protein phosphatase PP2C in the flagellum of Leishmania major: cloning and characterization. Parasitology Open 3, e15, 1-9. https://doi.org/10.1017/pao.2017.14

Received: 4 April 2017

Revised: 11 September 2017

Accepted: 12 September 2017

\section{Key words:}

Leishmania major; flagellum; protein phosphatase PP2C

\section{Author for correspondence:}

M.M. Aguirre-García, E-mail: maguirre@unam.mx

\section{A. R. Escalona-Montaño ${ }^{1}$, R. Pérez-Montfort ${ }^{2}$, N. Cabrera², R. Mondragón-Flores ${ }^{3}$, D. E. Vélez-Ramírez ${ }^{4}$, J. N. Gómez-Sandoval ${ }^{5}$, L. Gutiérrez-Kobeh¹, I. Becker ${ }^{1}$ and M. M. Aguirre-García ${ }^{1}$}

${ }^{1}$ Facultad de Medicina, Unidad de Investigación en Medicina Experimental, Universidad Nacional Autónoma de México, Dr. Balmis 148, Colonia Doctores C.P. 06726, Ciudad de México, México; ${ }^{2}$ Departamento de Bioquímica y Biología Estructural, Instituto de Fisiología Celular, Universidad Nacional Autónoma de México, C.P. 04510, Ciudad de México, México; ${ }^{3}$ Departamento de Bioquímica, Centro de Investigación y Estudios Avanzados (CINVESTAV-IPN), Av. Instituto Politécnico Nacional No. 2508, Col. San Pedro Zacatenco C.P. 07360, Ciudad de México, México; ${ }^{4}$ Posgrado en Ciencias Biológicas, Universidad Nacional Autónoma de México, Edificio D, 1o. Piso, Circuito de Posgrados, Ciudad Universitaria, Ciudad de México, México and ${ }^{5}$ Universidad Politécnica del Valle de Toluca Carretera Toluca-Almoloya de Júarez km. 5.6 Santiaguito Tlalcilalcali, Almoloya de Juárez, C.P. 50904, Estado de México, México

\begin{abstract}
The main goal of this work consisted in cloning, purifying and characterizing a protein phosphatase 2C (PP2C) from promastigotes of Leishmania major. The gene was cloned and amplified by PCR using specific oligonucleotides and the recombinant protein was purified by affinity chromatography. The peak with maximal protein concentration was analysed by sodium dodecyl sulphate-polyacrylamide gel electrophoresis and revealed a protein of $44.9 \mathrm{kDa}$ with PP2C activity. This activity was dependent on divalent cations $\left(\mathrm{Mg}^{+2}\right.$ and $\left.\mathrm{Mn}^{+2}\right)$ and was optimal at $\mathrm{pH}$ of $8 \cdot 5$, using phosphothreonine as the substrate. Sanguinarine inhibited the activity of the recombinant $L m \mathrm{PP} 2 \mathrm{C}$, while protein tyrosine phosphatase inhibitors had no effect. The recombinant $L m P P 2 C$ was used to generate polyclonal antibodies. These antibodies recognized a protein of $44.9 \mathrm{kDa}$ in different Leishmania species; the LmPP2C was localized in the flagellar pocket and the flagellum of promastigotes.
\end{abstract}

\section{Introduction}

The parasite Leishmania major is the causative agent of cutaneous leishmaniasis in the Old World. Leishmania survives and replicates within host macrophages and evades numerous host defences by inhibition of important cell functions, including the modulation of host cell signalling pathways through phosphorylation and dephosphorylation mechanisms. Protein phosphorylation and dephosphorylation processes are regulated by protein kinases and phosphatases, respectively, which generally occur on tyrosine, serine or threonine residues (Cohen, 2002; Wang et al. 2008). Protein phosphatases are classified in three families based on substrate specificity, sequence alignment, structure and their catalytic mechanism, which are: PPP (phosphoprotein phosphatases), PPM (metal-dependent protein phosphatases) and PTP (protein tyrosine phosphatases) (Moorhead et al. 2007). The PPP family consists of the phosphatases PP1, PP2A and PP2B. The PPM family contains type 2C protein phosphatases (PP2C) and pyruvate dehydrogenase phosphatase (PDP). The PP2C is a monomeric enzyme that requires the metal cations $\mathrm{Mg}^{+2}$ or $\mathrm{Mn}^{+2}$ for enzymatic activity (Das et al. 1996; Andreeva and Kutuzov, 2004; Schweighofer et al. 2004; Lammers and Lavi, 2007; Moorhead et al. 2007). In the human genome, 16 genes have been identified which generate 22 isoforms by a process of alternative splicing; each of these enzymes regulates distinct signalling pathways (Das et al. 1996). The roles of PP2C in eukaryotic cells are diverse and have been described in different organisms such as the plant Arabidopsis thaliana, in which 76 candidates of PP2C-type phosphatases were identified in its genome (Schweighofer et al. 2004). Different PP2C from A. thaliana participate in various signalling pathways, such as the one regulated by abscisic acid and the signalling pathways activated by mitogen protein (Mitula et al. 2015). In protozoan parasites such as Plasmodium falciparum, an unusual PP2C phosphatase (PfPP2C) was identified. It has two catalytic sites, one with serine and the other with threonine, with an identity between them of about 9\% (Mamoun et al. 1998). Sporozoites of Plasmodium yoelli and Plasmodium berguei, incubated with increasing concentrations of potassium, enhanced the infectivity of the parasites and the copy number of the transcripts for PP2C was increased, when compared with parasites not exposed to potassium in which the expression of the enzyme was kept at basal levels (Kumar et al. 2007). Toxoplasma gondii also has a protein phosphatase PP2C ( $\mathrm{TgPP} 2 \mathrm{C})$, which is secreted from the rhoptries, a group of secretory organelles involved in host cell invasion. Once inside the parasitophorous vacuole, $\mathrm{TgPP} 2 \mathrm{C}$ is transported to the nucleus of the host cell. In contrast, a PP2C knockout strain had reduced intracellular growth, which was reversed by complementation with the wild-type gene for PP2C (Gilbert et al. 2007). PP2C was cloned in the parasite 
Leishmania chagasi ( $L c \mathrm{PP} 2 \mathrm{C})$; however, there are no reports of its function in the parasite or in the host cell (Burns et al. 1993). The genome analysis of $L$. major predicted the existence of 45 phosphatases of the PPP family and 15 of the PPM family; however, the biochemical characterization and localization of these enzymes in this parasite have not yet been reported. We previously identified a membrane-bound PTP in $L$. major that differs in expression, activity and ultrastructural localization between the procyclic and metacyclic stages of the parasite life cycle (Aguirre-Garcia et al. 2006). We now report the cloning, expression, purification and biochemical characterization of PP2C from L. major. The enzyme was identified in different Leishmania species and its ultrastructural localization is shown in L. major promastigotes.

\section{Materials and methods}

\section{Culture of Leishmania spp promastigotes}

Leishmania major MHOM/SU/73/5-ASKH (a generous gift from Dr H. Moll, University of Würzburg, Germany), Leishmania (L.) mexicana MNYC/BZ/62/M379, Leishmania (L.) venezuelensis MHOM/VE/80/PMH3, Leishmania (L.) amazonensis IFLA/BR/ 67/PH8, Leishmania (V.) panamensis MHOM/PA/71/LS94, Leishmania (V.) brazilienzis MHOM/BR/75/M2903, Leishmania $(V$.$) donovani, [a generous gift from Dr Nancy Sarabia, Centro$ Internacional de Entrenamiento e Investigación Médica in Calí, Colombia (CIDEIM)], promastigotes were cultivated in RPMI 1640 medium, which contained penicillin $\left(100\right.$ units $\left.\mathrm{mL}^{-1}\right)$, streptomycin $\left(100 \mu \mathrm{g} \mathrm{mL}^{-1}\right)$ and $10 \%$ fetal bovine serum, at $26^{\circ} \mathrm{C}$ (all reagents were from Gibco, Invitrogen Corporation Carlsbad, CA, USA). The cultured promastigotes were washed twice with

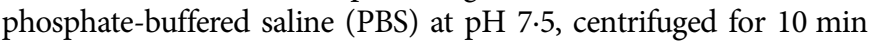
at $2500 \times \boldsymbol{g}$ at room temperature (RT).

\section{Extraction of DNA and amplification of the gene for PP2C from L. major}

Total DNA was extracted from L. major promastigotes using TRIZOL. The gene was amplified using the forward oligonucleotide (Fw) 5'ATGGGCATTCCACTTCCGA3' and reverse oligonucleotide (Rv) 5'TCACTGCGTCTGCTCACC3'. The PCR was performed using $100 \mu \mathrm{L}$ of the following reaction mixture: $1.5 \mathrm{mM} \mathrm{MgCl}_{2} ; 0.2 \mathrm{~mm}$ deoxynucleoside triphosphates; $100 \mathrm{ng}$ of the corresponding oligonucleotides; $10 \mathrm{ng}$ genomic DNA and one unit of Taq DNA polymerase (Invitrogen) using 40 cycles for $5 \mathrm{~min}$ at $94^{\circ} \mathrm{C}, 30 \mathrm{~s}, 1 \mathrm{~min}$ at $50.7^{\circ} \mathrm{C}, 30 \mathrm{~s}$ and $48 \mathrm{~s}$ at $72^{\circ}$ $\mathrm{C}$, and a final extension of $10 \mathrm{~min}$ at $72^{\circ} \mathrm{C}$. The gene was cloned into pET-23b expression plasmid using the Nde 1 and Hind III restriction sites. The gene was completely sequenced and transformed into BL21 (DE3) pLysS cells (Novagen, Madison, WI, USA). Bacteria containing the plasmid with the gene of protein phosphatase PP2C of L. major were grown in Luria-Bertani medium and selected for ampicillin resistance $\left(100 \mu \mathrm{g} \mathrm{mL}^{-1}\right)$ at $37^{\circ} \mathrm{C}$ allowing them to grow until the OD of the culture at $600 \mathrm{~nm}$ reached $0 \cdot 8-1 \cdot 0$. Expression of the recombinant protein was induced with $0.4 \mathrm{~mm}$ isopropyl-thio-b-D-galactopyranoside (IPTG) for $3 \mathrm{~h}$. After incubation, bacteria were harvested by centrifugation and processed immediately, or frozen at $-70{ }^{\circ} \mathrm{C}$ until use.

\section{Purification of recombinant PP2C from L. major (LmPP2C)}

Cell cultures in volumes of $100 \mathrm{~mL}$ were centrifuged and suspended in $50 \mathrm{~mL}$ lysis buffer $(50 \mathrm{~mm}$ Tris $\mathrm{HCl}, \mathrm{pH} 8 ; 300 \mathrm{~mm}$ $\mathrm{NaCl}$; $1 \mathrm{~mm}$ benzamidine, $100 \mu \mathrm{m}$ leupeptin, $2 \mu \mathrm{g} \mathrm{mL} \mathrm{m}^{-1}$ aprotinin and $5 \mathrm{~mm}$ imidazole). The suspension was sonicated five times for $40 \mathrm{~s}$ with resting periods of $2 \mathrm{~min}$ between each interval and $32 \%$ amplitude, using a ModelVCX 650 Ultrasonic processor (Ultrasonics, Inc.). The homogenate was centrifuged at $21000 \times \boldsymbol{g}$ for $1 \mathrm{~h}$ at $4{ }^{\circ} \mathrm{C}$ to obtain the supernatant with the soluble protein. The supernatant was loaded onto a Ni-charged column previously equilibrated with binding buffer (50 mm Tris- $\mathrm{HCl}, \mathrm{pH} 8 ; 300 \mathrm{~mm}$ $\mathrm{NaCl}$ and $5 \mathrm{~mm}$ imidazole). The recombinant protein ( $2 m \mathrm{PP} 2 \mathrm{C})$ was purified and eluted with an elution buffer (50 mM Tris- $\mathrm{HCl}$, $\mathrm{pH} 8 ; 300 \mathrm{~mm} \mathrm{NaCl}$ and $50-500 \mathrm{~mm}$ imidazole) and the protein concentration was quantified using the Bradford method (Bradford, 1976).

\section{Production of polyclonal antiserum}

Anti- $L m$ PP2C antibodies were generated in rabbits as previously described by Montfort and collaborators (Montfort et al. 1994). Before the immunization, the rabbits were bled, and pre-immune serum was collected. Briefly, rabbits were injected intramuscularly with $150 \mu \mathrm{g}$ of recombinant $L m \mathrm{PP} 2 \mathrm{C}$ emulsified in complete Freund's adjuvant; the same procedure was repeated 2 weeks later without adjuvant. The immunization was done with two weekly intramuscular injections, after which the animals were bled and antiserum was separated by centrifugation and stored at $-20{ }^{\circ} \mathrm{C}$. The pre-immune and immune sera were used for Western blot analysis. Rabbits were housed at the animal facilities of the Unidad de Investigación en Medicina Experimental de la Facultad de Medicina, UNAM, and their handling was done following the National Ethical Guidelines for Animal Health NOM-062-ZOO-1999 and the guidelines recommended for animal care by the Ethical Committee of the Medical School of the UNAM.

\section{Phosphatase activity assays}

p-NPP substrate

Acid phosphatase activity was determined as described by Dissing et al. (1979). Briefly, $0.7 \mu \mathrm{g}$ of recombinant $L m P P 2 C$ was incubated in the following buffers: $50 \mathrm{~mm}$ MES, pH 5-6.5; $50 \mathrm{~mm}$ MOPS, pH 7-7.5; 50 mM HEPES, pH 8; 50 mm TRIS, pH 8.5-9 and $50 \mathrm{~mm}$ CAPS, $\mathrm{pH} 10-11$ and added to $10 \mathrm{~mm}^{\mathrm{MgCl}} 2$ and $10 \mathrm{~mm} p$-nitrophenyl phosphate [ $p$-NPP] in a final volume of $100 \mu \mathrm{L}$ for $60 \mathrm{~min}$ at $37^{\circ} \mathrm{C}$. Afterwards, the reaction was stopped with $20 \mu \mathrm{L}$ of $2 \mathrm{~N} \mathrm{NaOH}$. The absorbance was read at $405 \mathrm{~nm}$ using a micro titre plate reader. Divalent cations $\left(10 \mathrm{mM} \mathrm{MgCl}_{2}\right.$ or $\mathrm{MnCl}_{2}$ ) were added in $50 \mathrm{~mm}$ HEPES, $\mathrm{pH} 8$.

\section{Phosphopeptides}

Tyrosine and serine/threonine phosphatase activity was assayed using Promega's non-radioactive tyrosine phosphatase assay system. The release of inorganic phosphate $\left(P_{i}\right)$ was monitored by measuring the absorbance of the molybdate-malachite greenphosphate complex. A $0.7 \mu$ g of recombinant $L m$ PP2C was incubated in a total volume of $100 \mu \mathrm{L}$ of assay buffer containing $50 \mathrm{~mm}$ HEPES pH 8.0 plus $10 \mathrm{~mm} \mathrm{MgCl}_{2}$. The reaction was started by adding $50 \mu \mathrm{M}$ Tyr phosphopeptide-1 substrate [END (pY) INASL], $50 \mu \mathrm{m}$ Thr [RRA (pT)VA] during $30 \mathrm{~min}$ at RT and stopped with $50 \mu \mathrm{L}$ molybdate dye/additive mixture. The optical density of the samples was read at $630 \mathrm{~nm}$, using a curve of phosphates as standard (Aguirre-Garcia et al. 2006).

\section{Effect of inhibitors of phosphatases on recombinant LMPP2C}

The activity of recombinant $L m \mathrm{PP} 2 \mathrm{C}(0.7 \mu \mathrm{g})$ was analysed in the presence of specific PTP inhibitors such as $200 \mu \mathrm{M}$ sodium orthovanadate, $200 \mu \mathrm{m}$ ammonium molybdate and $50 \mu \mathrm{m}$ sodium 
pervanadate. Additionally, serine/threonine phosphatase inhibitors were tested such as $5 \mathrm{~nm}$ calyculin and $1 \mu \mathrm{M}$ okadaic acid.

Sanguinarine, a specific inhibitor for PP2C, was used at $0 \cdot 1$, $0 \cdot 5,1,5,10$ and $20 \mu \mathrm{m}$. For the inhibition assays, $100 \mu \mathrm{L}$ of the reaction mixture was pre-incubated for $15 \mathrm{~min}$ at RT before adding the $p$-NPP substrate (all reagents from Sigma-Aldrich, St. Louis, MO, USA) and were incubated thereafter for another $60 \mathrm{~min}$ at $37^{\circ} \mathrm{C}$. Afterwards, the reaction was stopped with $20 \mu \mathrm{L}$ of $2 \mathrm{~N} \mathrm{NaOH}$. The absorbance at $405 \mathrm{~nm}$ was read using a micro titre plate reader. Recombinant PTP from Yersinia enterocolitica (YePTP) was used as a control of PTP activity (purchased from Calbiochem, La Jolla, CA, USA).

\section{SDS-PAGE and Western blot}

\section{Identification of the His-Tag in recombinant $\mathrm{LMPP} 2 \mathrm{C}$}

Total extract (TE) of bacteria was analysed by sodium dodecyl sulphate-polyacrylamide gel electrophoresis (SDS-PAGE) in 10\% acrylamide gels and then electro transferred to nitrocellulose membranes. The blots were incubated with a polyclonal HRP anti-His 6 -Tag antibody at a 1:1000 dilution in TBS-T $(200 \mathrm{~mm}$ Tris- $\mathrm{HCl}, 150 \mathrm{~mm} \mathrm{NaCl}, 0.005 \%$ Tween-20) and washed four times every $10 \mathrm{~min}$ with TBS-T.

\section{Identification of PP2C in TEs of L. (L.) mexicana, L. (N.)} panamensis, L. (V.) brazilienzis, L. (L.) venezuelensis, L. (V.) donovani, L. (L.) amazonensis, L. major promastigotes

All promastigotes were harvested by centrifugation at $2000 \times \boldsymbol{g}$ for $10 \mathrm{~min}$ and then washed three times with PBS. The pellet containing the parasites was suspended in cold lysis buffer $(10 \mathrm{~mm}$ imidazole $\mathrm{pH} 7 \cdot 2,2 \mu \mathrm{g} \mathrm{mL} \mathrm{L}^{-1}$ leupeptin, $10 \mu \mathrm{g} \mathrm{mL}^{-1}$ aprotinin, $2 \mathrm{~mm}$ benzamidine) and then sonicated (TE). Afterwards, $10 \mu \mathrm{g}$ of TE from different Leishmania species and were analysed by SDS-PAGE in $10 \%$ acrylamide gel and electro transferred onto nitrocellulose membranes. The PP2C protein was used as a control. These were washed with TBS-T and blocked by treatment with $5 \%$ milk in TBS-T for $1 \mathrm{~h}$; then they were incubated with antibodies against $L m P P 2 C$ using a dilution of $1: 1000$ in $1 \%$ milk in TBS-T overnight at $4{ }^{\circ} \mathrm{C}$. After this incubation, the membranes were washed with TBS-T and incubated with the secondary HRP-goat anti-rabbit IgG antibody (Biomeda, Foster City, CA, USA) at a dilution of 1:5000 in TBS-T with $3 \%$ of milk. The membranes were finally washed 10 times in TBS-T.

Bands were detected using enhanced chemiluminescent substrate (Super-Signal West Pico Chemiluminescent Substrate, Pierce, Rockford, IL, USA), following the manufacturer's instructions.

\section{Fluorescence microscopy}

Leishmania major promastigotes were washed with PBS and allowed to adhere to poly-L-lysine-coated cover slides for $90 \mathrm{~min}$. They were then fixed with $2 \%$ paraformaldehyde in PBS for $30 \mathrm{~min}$ at RT and washed three times with PBS. Afterwards, these cells were permeabilized with $5 \%$ triton X-100 and blocked with $5 \%$ BSA for $30 \mathrm{~min}$. They were then incubated overnight at $4{ }^{\circ} \mathrm{C}$ with antibodies against the recombinant LmPP2C using a 1:100 dilution. The parasites were washed with PBS after the incubation and stained with fluorescein isothiocyanate (FITC)-conjugated anti-rabbit IgG secondary antibodies at a 1:200 dilution. Cells were counterstained with $4^{\prime}, 6^{\prime}-2$ diamidino-2-phenylindole (DAPI) at a 1:1000 dilution in PBS. Cover slides were mounted with vectashield mounting medium (Vector Laboratories, Inc., Burlingame, CA, USA) and observed in a fluorescence microscope (Axioskop 2 mot plus, Carl Zeiss, Germany). The images were recorded in an Axiocam HR digital camera and processed with the Axiovision software (Carl Zeiss, Version 4.8), (Gomez de Leon et al. 2014).

\section{Immunolocalization of PP2C by immune electron microscopy (IEM)}

Detection of PP2C in L. major promastigotes was achieved by electron microscopy (Gomez de Leon et al. 2014). Briefly, promastigotes were washed with PBS and then fixed with a mixture of $4 \%$ paraformaldehyde and $0 \cdot 1 \%$ glutaraldehyde in PBS for $1 \mathrm{~h}$ at RT. Once washed, the promastigotes were gradually dehydrated in ethanol and embedded in LR White resin (London Resin, Polysciences, Inc., Warrington, PA, USA). Promastigotes in resin were deposited in plastic moulds and were polymerized overnight, under ultraviolet light, at $4{ }^{\circ} \mathrm{C}$. Thin sections of the blocks were obtained in an Ultracut $\mathrm{E}$ ultra-microtome (Reichert Jung, Austria) and then mounted on Formvar-covered nickel grids. Immunogold labelling was carried out by flotation of the mounted sections on drops of the respective solutions; nonspecific labelling was diminished by incubation with $1 \%$ skim milk and PBS-T (PBS and 0.05\% Tween-20) for $30 \mathrm{~min}$. Grids with the sections were incubated with the antibody against $L m$ PP2C at a 1:10 dilution in PBS-T for $1 \mathrm{~h}$ at $\mathrm{RT}$ and overnight at $4{ }^{\circ} \mathrm{C}$. Grids were washed with PBS-T and then incubated with a goat anti-rabbit polyclonal antibody coupled to $10 \mathrm{~nm}$ gold particles for $2 \mathrm{~h}$ at RT (Zymed, Thermo Scientific, PA, USA) (1:40 dilution in PBS-T). After thorough washings in PBS and distilled water, sections were contrasted with $2 \%$ uranyl acetate and a saturated solution of lead citrate and then examined with a transmission electron microscope (TEM, JEOL 1400x, JEOL Ltd, Japan). As negative control, sections were incubated with pre-immune rabbit serum diluted in PBS-T and then with the secondary antibody coupled to gold particles.

The identification of the subcellular structures positive for PP2C was performed using thin sections of parasites that were processed to preserve the ultrastructure. (Gomez de Leon et al. 2014). Briefly, promastigotes were fixed for $1 \mathrm{~h}$ in $2.5 \%$ glutaraldehyde. After thorough rinsing in PBS, parasites were post-fixed for $1 \mathrm{~h}$ in $1 \% \mathrm{OsO}_{4}$ at $4{ }^{\circ} \mathrm{C}$, rinsed, gradually dehydrated in ethanol, and finally embedded in Spurr's resin. Thin sections were obtained with an Ultracut $\mathrm{E}$ ultramicrotome and stained with uranyl acetate and lead citrate. Copper grids with the sections were examined in the TEM at $80 \mathrm{keV}$. Digital images were obtained and processed with Adobe Photoshop software (USA).

\section{Bioinformatic analysis}

Homology modelling was performed using the SWISS-MODEL server (http://swissmodel.expasy.org/interactive); the model was validated with the Mod Eval software version master.e8f19a7 (https://modbase.compbio.ucsf.edu/evaluation//), and the structure obtained was edited using the Swiss-PDBViewer programme version 4.1 (http://www.expasy.org/spdbv/). Secondary structure prediction was carried out using PSIPRED Protein Sequence Analysis Workbench version 3.3 (http://bioinf.cs.ucl.ac.uk/psipred/) (Melo et al. 2002; Arnold et al. 2006; Shen and Sali, 2006; Bordoli et al. 2009; Guex et al. 2009; Buchan et al. 2013; Biasini et al. 2014).

\section{Phylogenetic analysis of L. major PP2CS}

The non-rooted phylogenetic tree was constructed using the MEGA 6 programme from the alignment of 15 amino acid sequences PP2Cs present in the L. major genome with the protein sequence of the LmxM.25.0.750 gene of L. mexicana and the protein sequence of the human PP2C (PPM1A, NP_066283.1), which was used as seed. 


\section{Results}

\section{Cloning, expression and purification of PP2C of L. major}

In order to determine the primary structure of PP2C homologue from L. major, forward and reverse primers were constructed from the sequence of the LmjF.25.0750 gene in TriTrypDB, the database of Trypanosomatids (tritrypdb.org). A fragment of $1200 \mathrm{bp}$ was amplified from L. major DNA using PCR. The pET-23b (+) expression vector containing a C-terminal $\mathrm{His}_{6}$ Tag was transformed into BL21 strain of Escherichia coli for expression and purification of the PP2C fusion protein. The transformed BL21 cells were grown and induced with $1 \mathrm{~mm}$ IPTG for $3 \mathrm{~h}$ at $30^{\circ} \mathrm{C}$, the recombinant protein was observed in gels stained with Coomassie blue (Fig. 1A, lanes 2 and 3), in contrast to cells in which the expression of the protein was not induced (Fig. 1A, lane 1). The presence of the histidine tag in the recombinant protein was verified by Western blot with specific antibodies that recognized the C-terminal $\mathrm{His}_{6}$ Tag (Fig. 1B, lanes 2 and 3), which was negative in non-induced cells (Fig. 1B, lane 1). TE of
A

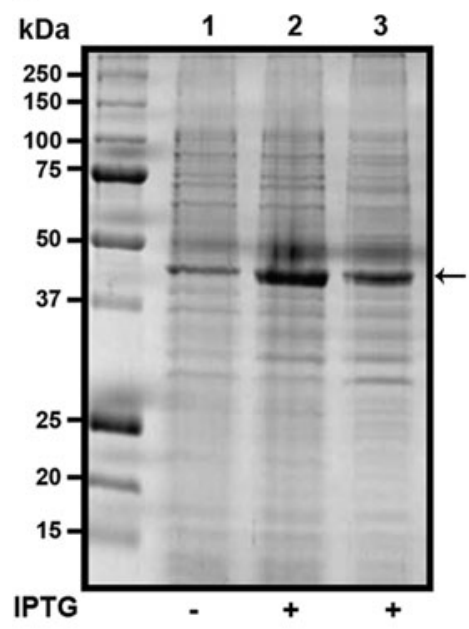

C

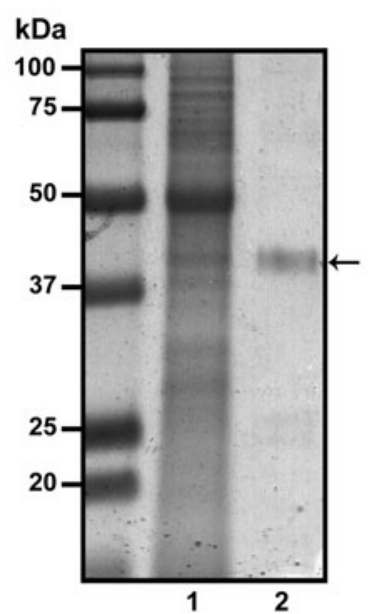

B

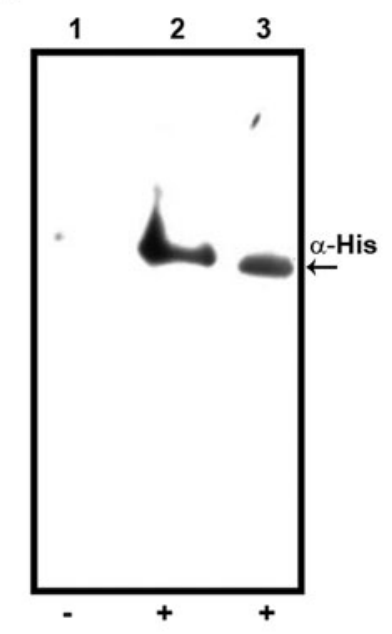

D

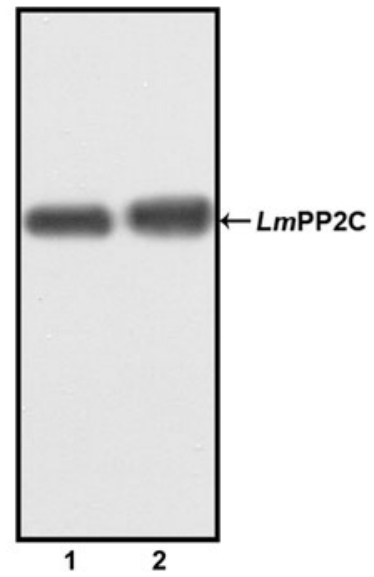

Fig. 1. Expression, purification and identification of PP2C of Leishmania major ( $L m$ PP2C). (A) Expression of $L m$ PP2C in different fractions of Escherichia coli cells. Crude extract prepared from non-induced E. coli cells BL21 (1), E. coli cells induced with IPTG (2) and supernatant (3). SDS-PAGE gel was stained with Coomassie-blue dye. (B) Western blot analysis of the same sample used above: crude extract prepared from non-induced E. coli cells BL21 (1), E. coli cells induced with IPTG (2) and supernatant (3). The C-terminal His-Tag was detected using a monoclonal antibody. (C) SDS-PAGE gel of TE of $L$. major (1) and $L m$ PP2C purified (2) were stained with Coomassie Blue. (D) Western blot of TE of L. major (1), and purified Lm PP2C (2), using polyclonal antibodies against $L m$ PP2C.
L. major promastigotes and recombinant protein were analysed by SDS-PAGE and stained with Coomassie blue (Fig. 1C, lanes 1 and 2). This result showed that the purified protein had the expected molecular mass of $44.9 \mathrm{kDa}$. The anti- $L m \mathrm{PP} 2 \mathrm{C}$ antibodies were checked by Western blot using TE of $L$. major and purified $L m$ PP2C. These antibodies recognized a $44.9 \mathrm{kDa}$ protein in both samples (Fig. 1D, lanes 1 and 2).

\section{Multiple sequence alignment}

Using Clustal W multiple-sequence alignment, the sequence of the cloned $L m$ PP2C revealed that it has $98 \%$ similarity with the sequence of $\mathrm{PP} 2 \mathrm{C}$ of $L$. chagasi. It also demonstrated that the complete $L m P P 2 C$ open reading frame shares 11 distinct conserved motifs in the enzymes belonging to this family (Fig. 2A).

Furthermore, both HsPP2C and LmPP2C have conserved amino acids for catalytic activity such as: the aspartic acid residues involved in the coordination of $\mathrm{Mg}^{+2}$ and $\mathrm{Mn}^{+2}$ cations. The catalytic site of PP2C is localized in a cleft between two central $\beta$ sheets formed by aspartic acids D38, D55, D221, D265, arginine R33 and glutamic acid E37 (Fig. 2B). Identical residues were identified at these positions in all aligned sequences (Fig. 2A). These residues were confirmed to be present in $L m P P 2 C$.

\section{Phylogenetic tree analysis}

To compare the protein LmjF.25.0750 analysed in this work with the members of the PP2C in $L$. major family and for the identification of conserved residues, a multiple-sequence alignment was constructed using the 15 L. major PP2C, LmxM.25.0750 and the human PP2C (PPM1A). Similarity relationships among the amino acids sequences were obtained and we identified characteristic motifs preserved by evolution. A total of 11 conserved signature motifs were identified that seem to correspond to structural elements and exposed functional residues of PP2C proteins (data not shown). To investigate the phylogenetic relationships of PP2C genes between $L$. major phosphatases, L. mexicana PP2C and the human PPM1A, we constructed a phylogenetic tree based on the alignments of PP2C domains using the maximum likelihood method. The phylogenetic analyses indicated that the $15 \mathrm{Lm}$ PP2C proteins were divided into four groups (Fig. 2C, I-IV). The LmjF 25.0750 recombinant protein clustered together with LmxM.25.0750 (Fig. 2C, III), while the nine Lmj phosphatases formed an independent group (Fig. 2C, IV). There was a cluster of three proteins in group I, whereas $\mathrm{LmjF} 36.1230$ was in an independent branch (Fig. 2C, II).

\section{Biochemical characterization of LmPP2C}

\section{Cation dependence}

Phosphatases PP2C are usually monomeric enzymes that require metal cations such as $\mathrm{Mg}^{+2}$ or $\mathrm{Mn}^{+2}$ for their enzymatic activity. We analysed the activity of $L m P P 2 C$ with the substrate $p$-NPP in the presence or absence of divalent cations. We observed that $L m$ PP2C showed higher phosphatase activity in the presence of $\mathrm{MnCl}_{2}$, compared with $\mathrm{MgCl}_{2}$ (Fig. 3A).

\section{Substrate specificity}

Substrate specificity was tested by dephosphorylation assays using peptides phosphorylated in tyrosine and threonine residues. It was observed that $L m \mathrm{PP} 2 \mathrm{C}$ dephosphorylate preferentially the threonine substrate (Fig. 3B), whereas the tyrosine substrate was not dephosphorylated. 

A
LmPP2C
LCPP2C
HsPP2C

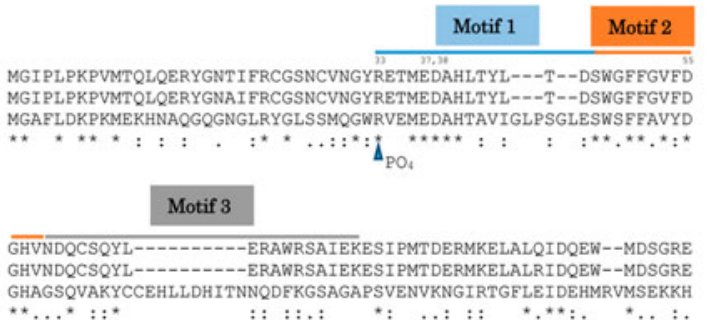

LCPP2C GHVNDQCSQYL---------ERAWRSAIEKESI PMTDERMKELALRIDQEW--MDSGR: HSPP2C GHAGSQVAKYCCEHLLDHITNNQDFKGSAGAPSVENVKNGIRTGFLEIDEHMRVMSEKKH

\section{Flap domain}

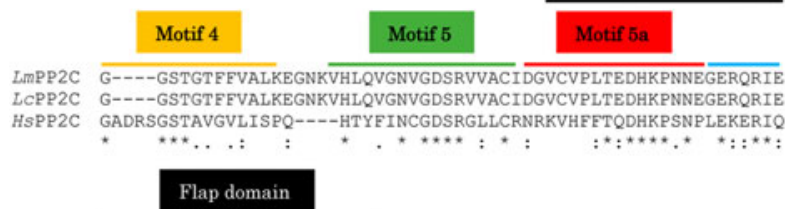

\section{Flap domain}

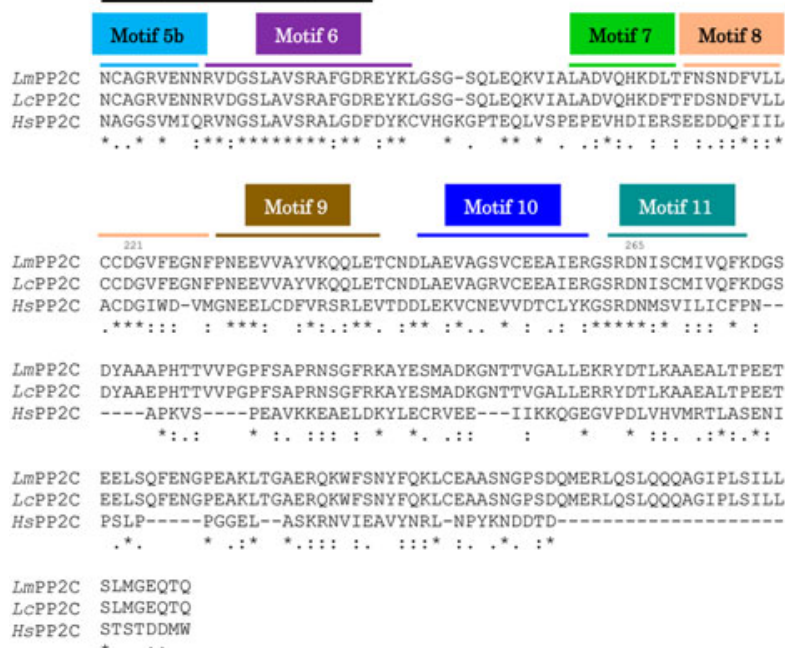

B
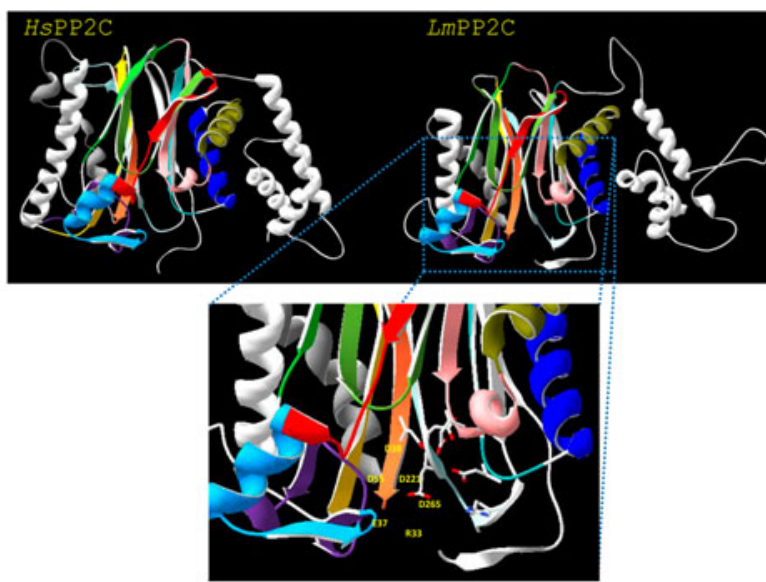

C

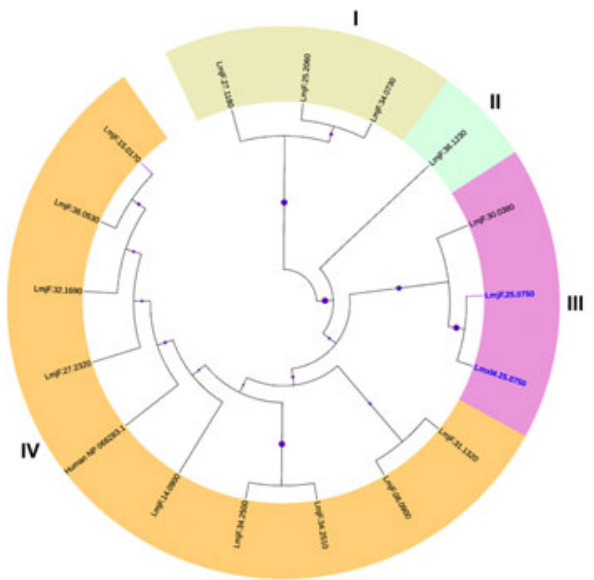

Fig. 2. Multiple sequence alignments of human, Leishmania major and Leishmania chagasi PP2C and phylogenetic analysis of $L$. major PP2Cs. (A) Multiple sequence alignment of Human PP2C (HsPP2C), L. major ( $L m P P 2 C)$ and L. chagasi (LCPP2C). Alignment of the catalytic domain sequences was performed using the programme CLUSTAL W. The most important residues of the three PP2C are indicated with numbers and motifs with colours: motif 1 (blue line), motif 2 (orange line), motif 3 (grey line), motif 4 (yellow line), motif 5 (dark green line), the Flap domain is indicated by a black line. Motifs $5 a$ and $5 b$ are shown with a red and dark blue line respectively, motif 6 (purple line), motif 7 (clear green line), motif 8 (pink line), motif 9 (brown line), motif 10 (blue line) and motif 11 (water green line). (B) Ribbon diagram of $H s P P 2 C$ and $L m P P 2 C$. The catalytic site of $L m P P 2 C$ was amplified, showing the important amino acids. (C) Phylogenetic analysis of $L$. major PP2Cs. The non-rooted phylogenetic tree was constructed in the MEGA 6 programme from the alignment of 15 amino acid sequences PP2Cs present in the L. major genome with the protein sequence of the LmxM.25.0.750 gene of Leishmania mexicana and the protein sequence of the human PPM1A (NP_066283.1). Seventeen proteins were grouped into four groups and designated with different colour (I-IV). The evolutionary history was inferred using the maximum probability, method based on the Le_Gascuel_2008 model.

\section{Optimum $\mathrm{pH}$}

The influence of $\mathrm{pH}$ on the enzymatic activity for recombinant $L m$ PP2C was evaluated using two different substrates: $p$-NPP and the phosphothreonine peptide [RRA (pT) VA] in different buffers. The results showed that the optimal activity of PP2C phosphatase reached at $\mathrm{pH} 8.5$ using $p$-NPP as substrate, while the phosphothreonine substrate showed the maximum at $\mathrm{pH} 7$ (Fig. 3C).

\section{Effect of various inhibitors of phosphatases on the activities of LMPP2C}

In order to characterize if the phosphatase activity is due to PTP or PP2C activity, we used different phosphatase inhibitors: orthovanadate, molybdate and pervanadate for PTP and calyculin, okadaic acid and sanguinarine for serine/threonine phosphatases.

$L m$ PP2C was not inhibited by the specific PTP inhibitors (Fig. 4A), which contrasts with the YePTP that was completely inhibited by these compounds (Fig. 4A). Calyculin and okadaic acid did not inhibit $L m \mathrm{PP} 2 \mathrm{C}$ or YePTP (Fig. 4A). However, sanguinarine, the specific inhibitor of PP2C activity, inhibited
$L m$ PP2C in a dose-dependent manner $(0 \cdot 1-20 \mu \mathrm{M})$, with a complete inhibition at a concentration of $10 \mu \mathrm{M}$ (Fig. 4B).

\section{Western blot reactivity of recombinant $L M P P 2 C$}

Antibodies were prepared against the recombinant $L m \mathrm{PP} 2 \mathrm{C}$ $(\alpha-L m \mathrm{PP} 2 \mathrm{C})$ and used to identify the PP2C protein in TE promastigotes from different Leishmania species: $L$. (L.) mexicana, L. (V.) panamensis, L. (V.) brazilienzis, $L$. (L.) venezuelensis, $L .(V$. donovani, $L$. (L.) amazonensis, L. major and LmPP2C. In all Leishmania species, a $44.9 \mathrm{kDa}$ protein was identified (Fig. $5 \mathrm{~A}$, lanes 1-7) which had the same molecular mass as LmPP2C (Fig. 5A, lane 8). Tubulin, as a loading control, was included in the same experiment.

\section{Immunolocalization of $P P 2 C$ in L. major promastigotes by} immunofluorescence

The analysis of the distribution of the PP2C in promastigotes of L. major was performed by indirect immunofluorescence. Parasites were observed using phase contrast microscopy (Fig. 5B, panel a). 

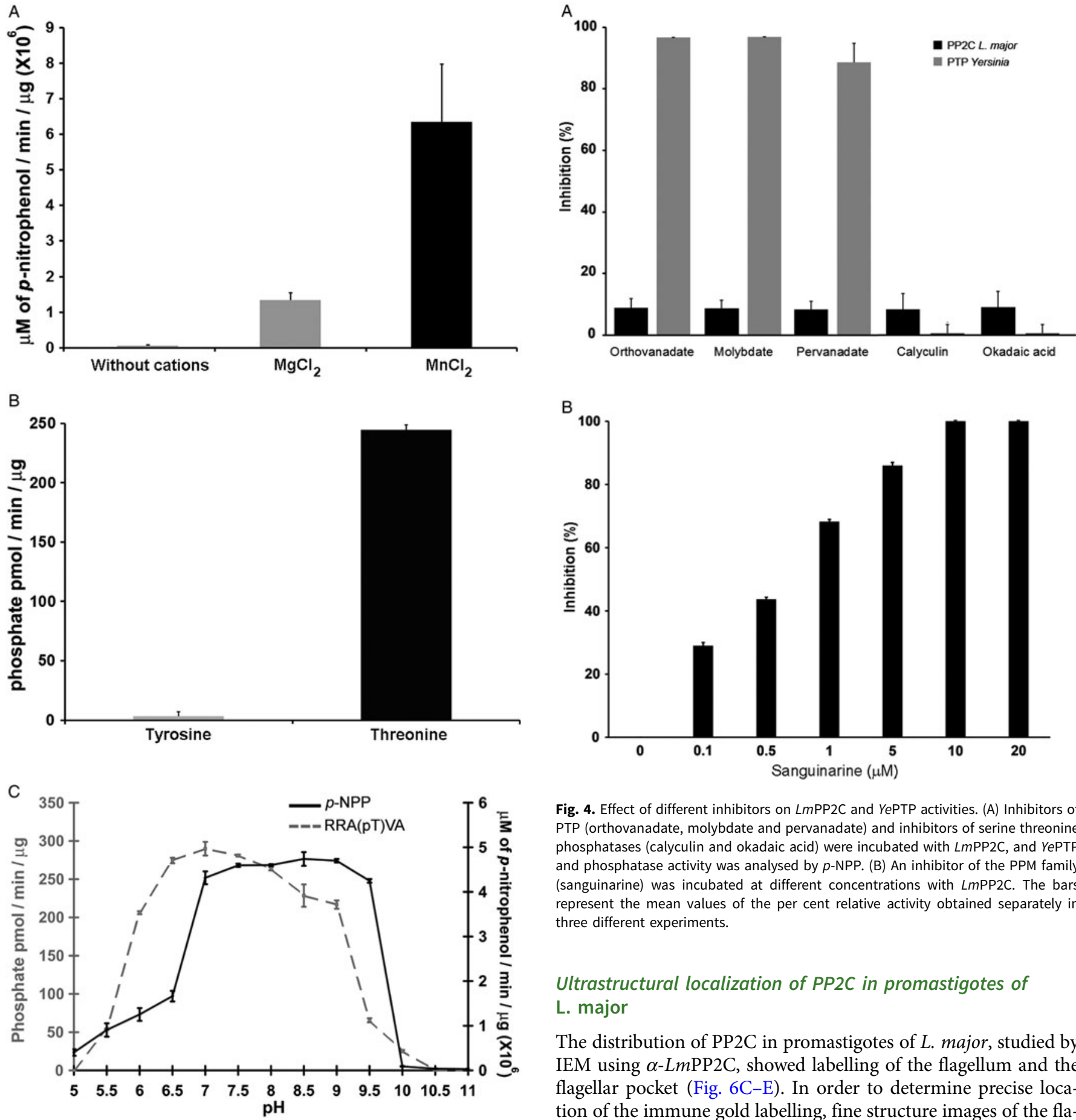

Fig. 4. Effect of different inhibitors on $\angle m P P 2 C$ and YePTP activities. (A) Inhibitors of PTP (orthovanadate, molybdate and pervanadate) and inhibitors of serine threonine phosphatases (calyculin and okadaic acid) were incubated with LmPP2C, and YePTP and phosphatase activity was analysed by $p$-NPP. (B) An inhibitor of the PPM family (sanguinarine) was incubated at different concentrations with $L m P P 2 C$. The bars represent the mean values of the per cent relative activity obtained separately in three different experiments.

\section{Ultrastructural localization of PP2C in promastigotes of L. major}

The distribution of PP2C in promastigotes of L. major, studied by IEM using $\alpha-L m P P 2 C$, showed labelling of the flagellum and the flagellar pocket (Fig. 6C-E). In order to determine precise location of the immune gold labelling, fine structure images of the flagellar pocket and the flagellum were done in longitudinal and transverse sections (Fig. 6A and B). Negative controls with pre-

Fig. 3. Biochemical characterization of $L m P P 2 C$. (A) The effect of $\mathrm{MgCl}_{2}$ and $\mathrm{MnCl}_{2}$ on $L m P P 2 C$ activity was measured under standard conditions using $p$-NPP $10 \mathrm{~mm}$ as a substrate. (B) Hydrolysis of [END (pY) INASL] and Thr [RRA (pT) VA] by LmPP2C. (C) Determination of optimum $\mathrm{pH}$ for the activity of $L \mathrm{mPP} 2 \mathrm{C}$. PP2C was incubated with the appropriate buffers at different $\mathrm{pH}(5-11)$ in the presence of $10 \mathrm{~mm} \mathrm{MgCl}$ and different substrates: $p$-NPP and RRA(pT) VA.

The nucleus was stained with DAPI (Fig. 5B, panel b). In several parasites, the distribution of $\mathrm{PP} 2 \mathrm{C}$ showed a fluorescent pattern confined to the flagellum and to the flagellar pocket (big arrows). Interestingly, some parasites exhibited a three-band pattern located in the cell body (small arrows) without staining of the flagella (Fig. 5B, panel c). The merge of both: nuclei and PP2C labelling, is shown in panel d (Fig. 5B). The negative control with pre-immune serum showed no labelling of the parasite (data not shown). site (data not shown).

\section{Discussion}

In recent years, the number of PP2C family members has grown steadily, and more interesting features, phenotypes and potential clinical applications have been described for the family of phosphatases. Orthologs of human PP2C can be found in virtually all organisms, ranging from mammals, insects, plants, bacteria and yeasts to parasites. This conservation throughout evolution indicates that these enzymes probably play important roles in regulating key cellular signalling events (Su and Forchhammer, 2013). The genome of L. major was reported in 2005 (Ivens et al., 2005), and 2 years later, the first analysis of catalytic domains of 


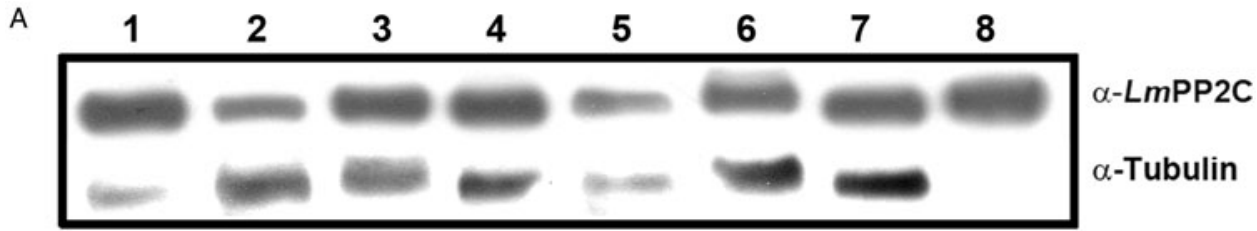

B
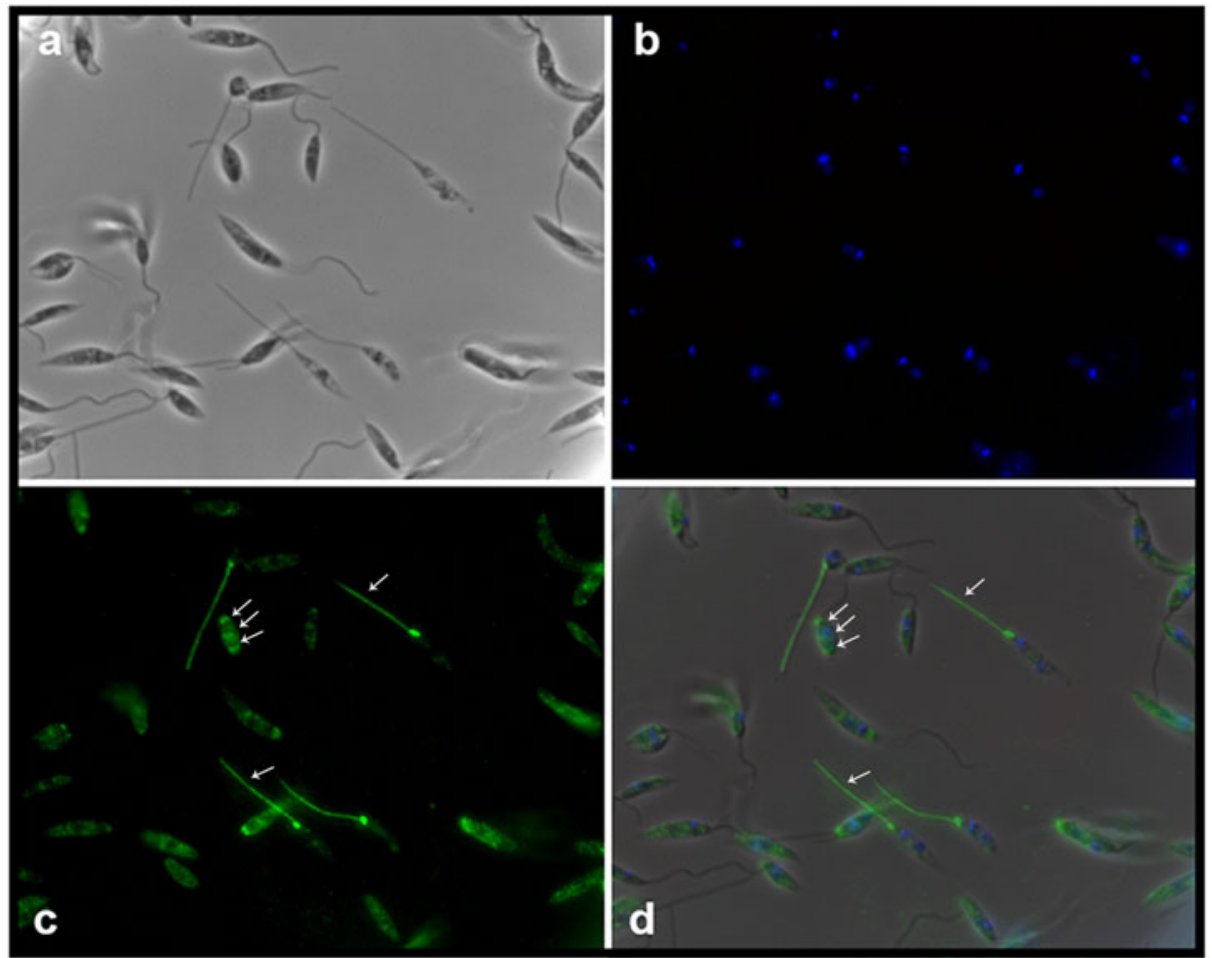

Fig. 5. $\mathrm{PP} 2 \mathrm{C}$ : immunodetection in TE promastigotes from different Leishmania species and immunolocalization in promastigotes. (A) Immunodetection of PP2C protein in TE promastigotes from Leishmania (L.) mexicana (1), Leishmania (V.) panamensis (2), Leishmania (V.) brazilienzis (3), Leishmania (L.) venezuelensis (4), Leishmania (V.) donovani(5), Leishmania (L.) amazonensis (6), Leishmania major (7), promastigotes Lm PP2C recombinant was used as control (lane 8). Tubulin as a loading control. (B) Immunolocalization of PP2C in L. major promastigotes by immunofluorescence microscopy. Parasites were observed in phase contrast (panel a), the nucleus was stained with DAPI (panel b). Distribution of $L m$ PP2C was determined by using an antibody against PP2C and then evidenced with a secondary antibody conjugated to FITC (panel c). Inset $d$ represents the merge of the different staining conditions. Scale bar $=5 \mu \mathrm{m}$.

protein phosphatases in Trypanosomatids was also reported. The authors identified 86 phosphatases in Trypanosoma cruzi, 78 in Trypanosoma brucei and 88 in L. major. In the case of L. major, 58 serine/threonine phosphatases were reported, of which 30 were from the PPP family, 13 were phosphatases that dephosphorylate the carboxy-terminal domain of RNA polymerase II (F-cell production eukaryotic-like phosphatases) and 15 were PP2C eukaryotic-like phosphatases (Brenchley et al. 2007). Currently, the function of each of the 15 different PP2C from L. major is unknown.

In the present work, we cloned PP2C from $L$. major and generated a recombinant His-Tag PP2C fusion protein. $L m P P 2 C$ was expressed in BL21 E. coli cells and purified. The biochemical characterization of $L m P P 2 C$ showed it had a molecular mass of $44.9 \mathrm{kDa}$, an activity optimum at alkaline $\mathrm{pH}$, that it could specifically dephosphorylate a threonine substrate and had a dependence on divalent cations $\left(\mathrm{Mg}^{+2}\right.$ and $\left.\mathrm{Mn}^{+2}\right)$ for enzymatic activity; all of which are also biochemical characteristics of PP2C from mammalian cells. In all the PP2C, the catalytic domains are important because they include conserved motifs that contain invariant residues involved in the binding of the two metal cations (D42, 66, 202 and 240) and on the phosphate group of the substrate (R37) (Das et al. 1996). Alignment of the phosphatase domains of T. gondii with other PP2C proteins showed an absence of two conserved aspartic acid residues that are important for metal binding and typical PP2C activity (Gilbert et al. 2007). The absence of these residues caused that the recombinant $\mathrm{PP} 2 \mathrm{C}$ protein showed low metal-dependent phosphatase activity.

Examination of the primary sequence of $L m \mathrm{PP} 2 \mathrm{C}$ shows homology to other PP2C proteins. Additionally, the conservation of the essential catalytic residues between human PP2C $(H s$ PP2C) and $L m$ PP2C suggests that the latter is a PP2C from the PPM family. The analysis of sequences for the PPM phosphatase proteins has identified 11 motifs, which are also conserved between the different phosphatases. The sequence alignment of $L m P P 2 C$ with the consensus sequences of $H s \mathrm{PP} 2 \mathrm{C}$ and $L c \mathrm{PP} 2 \mathrm{C}$ phosphatases indicated that $L m$ PP2C contains also 11 conserved motifs characteristic of $\mathrm{PP} 2 \mathrm{C}$. In other microorganisms, such as bacteria, it has been observed that motifs $5 \mathrm{a}$ and $5 \mathrm{~b}$ (Flap domain) of the $\mathrm{PP} 2 \mathrm{C}$ protein are absent, thus affecting the enzymatic activity (Schlicker et al. 2008). On the other hand, PP2C $\alpha$ has a Flap domain, which is inserted between strands $\beta 8$ and $\beta 9$ of the catalytic domain (Das et al. 1996; Pullen et al. 2004; Schlicker et al. 2008). This domain, with conserved motifs $5 \mathrm{a}$ and $5 \mathrm{~b}$, is found in PP2C phosphatases, like the mitochondrial PDP and the phosphatase domains of fungal adenylate cyclases, but is absent in bacterial SpoIIE-type phosphatases (Kennelly, 2001; Pullen et al. 2004). The function of the Flap domain is uncertain, but appears to be involved in substrate recognition (Schlicker et al. 2008; Su et al. 2011). 

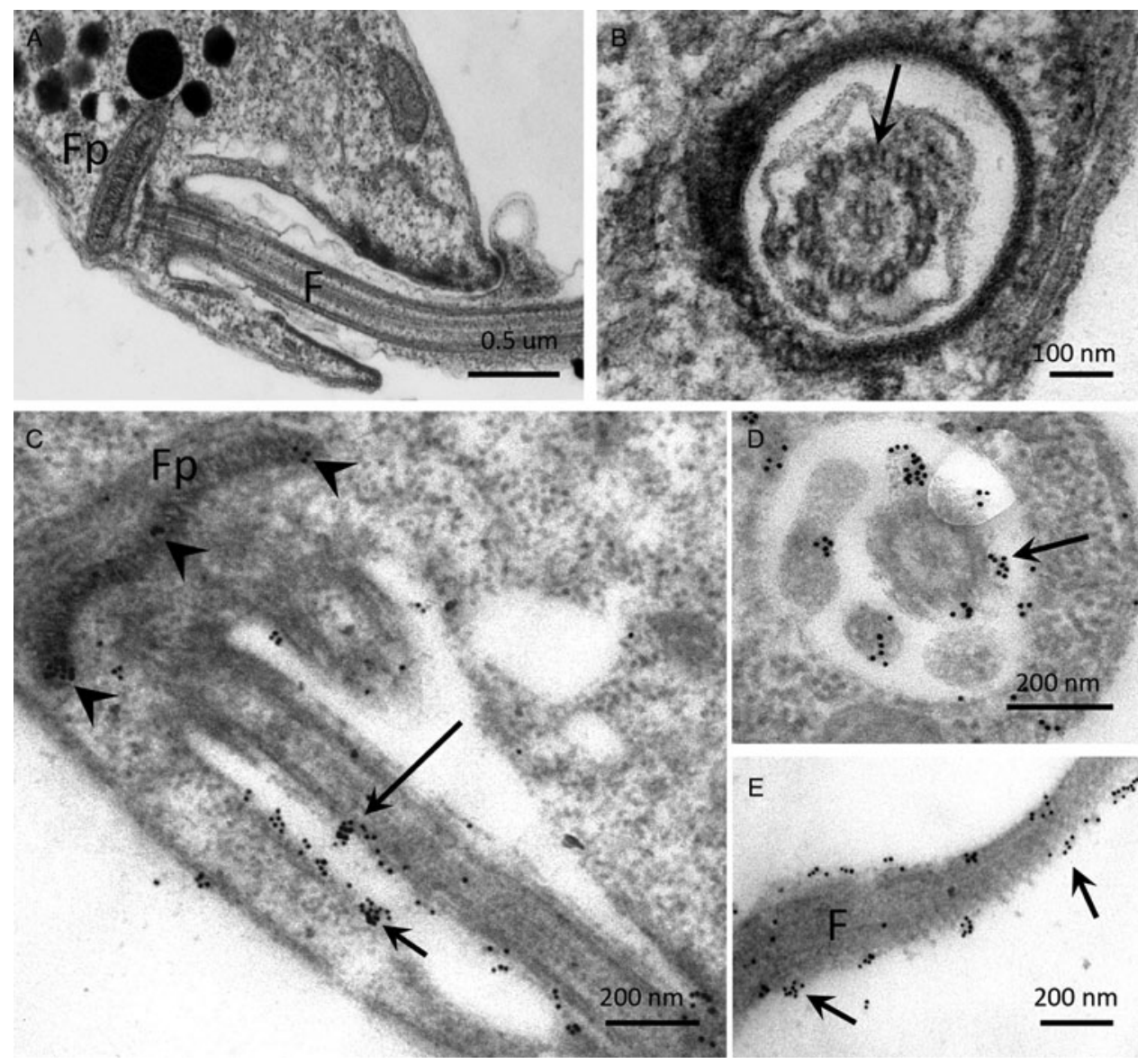

Fig. 6. IEM localization of $\angle m P P 2 C$ in promastigotes. Insets (A) and (B) correspond to controls of ultrastructure of the flagellar pocket of promastigotes seen in longitudinal and transverse thin sections, respectively. Insets (D, E) correspond to the immuno-gold labelling of the $L m P P 2 C$ in magnified zones of the promastigote in longitudinal (inset C) and transverse (inset D) views of the flagellar pocket. Inset (E) corresponds to the labelling of $L m P P 2 C$ in a magnified zone of the flagellum. Scale bar $=200 \mathrm{~nm}$.

The phylogenetic analysis showed that the 15 L. major PP2C are clustered in four groups. Surprisingly, the recombinant protein LmjF.25.0750 and the different species LmxM.25.0750 are grouped in the same cluster suggesting that they share a common ancestor, and, more distant in the same cluster, is LmjF.30.0380. The groups in the phylogenetic tree of $\mathrm{PP} 2 \mathrm{C}$ represent proteins with highly similar sequences; however, to the best of our knowledge, there are no reports of their structure, localization in the parasite or functional results.

Using a general substrate for phosphatases, $L m P P 2 C$ showed a strong preference for $\mathrm{Mn}^{+2}$, in comparison to $\mathrm{Mg}^{+2}$. The preference for this cation has also been observed in other PP2C enzymes like the STP1 phosphatases of Streptococcus agalactiae and Pseudomonas aeuroginosa (Mukhopadhyay et al. 1999; Rajagopal et al. 2003). In vitro assays using $p$-NPP as a substrate showed that the highest specific activity of $L m \mathrm{PP} 2 \mathrm{C}$ was at $\mathrm{pH} 8.5$ in the presence of $\mathrm{Mg}^{+2}$; however, when using phosphotreonine, the optimal $\mathrm{pH}$ was observed at 7.0. It is well known that PP2C of pathogenic microorganisms show alkaline optimal $\mathrm{pH}$, as has been observed in Prp C from Bacillus subtilis and PPC6803 from Synechocystid (Obuchowski et al. 2000; Ruppert et al. 2002). For $L m P P 2 C$, both divalent cations $\left(\mathrm{Mg}^{+2}\right.$ and $\left.\mathrm{Mn}^{+2}\right)$ are important for catalytic activity at alkaline $\mathrm{pH}$.

We show novel data on the ultrastructural localization of PP2C in L. major promastigotes, which was found in the flagellum, the flagellar pocket and in the micro axoneme. The heterogeneous staining pattern of the parasites may be due to different development stages of the parasite, since the culture was not synchronized. In other Trypanosomatid parasites, such as Trypanosoma rangeli, a PTP was reported to be associated with the parasite flagellum, yet the function remains unknown (Prestes et al. 2012). In most of these cells, the PP2C enzymes are mainly localized in the cytosol, and in the case of T. gondii, the parasite also uses secretion from the rhoptries during invasion, in order to deliver a parasite-derived PP2C into the host cell and target it to the host nucleus (Gilbert et al. 2007).

The localization of PP2C in the flagellum of $L$. major, an important structure for differentiation in Trypanosomatids, is noteworthy since the phosphatase could potentially exert a regulatory function within this organelle. Yet the role of $L$. major PP2C remains to be established and functional tests are warranted to determine its biological role in the parasite.

Acknowledgements. This work is one of the requirements to obtain the Ph.D. degree in Posgrado en Ciencias Biológicas (UNAM) for Alma Reyna Escalona Montaño who was the recipient of doctoral fellowship from CONACyT México (fellowship165409, CVU 165409).

The authors gratefully acknowledge Marco Gudiño Zayas, Norma Salaiza Suazo, José Delgado Domínguez, Marco Benítez Rosas, Rocely Cervantes Sarabia, Augusto González Canto, Arturo Wilkins Rodríguez and Angélica Leticia Serrano Ahumada for technical assistance from the Unidad de Investigación en Medicina Experimental, Facultad de Medicina, UNAM. Thanks to Mónica Mondragón, Ricardo Mondragón González and Sirenia González from the Biochemistry Department and Electron Microscopy Facility-LANSE, respectively, at CINVESTAV, México, for the technical support.

Financial support. This work was supported partially by grants 152433 from Consejo Nacional de Ciencia y Tecnología (CONACyT) of México and IN220816 from DGAPA-PAPIIT to MMAG. 


\section{References}

Aguirre-Garcia MM, Escalona-Montano AR, Bakalara N, Perez-Torres A Gutierrez-Kobeh L and Becker I (2006) Leishmania major: detection of membrane-bound protein tyrosine phosphatase. Parasitology 132, 641-649.

Andreeva AV and Kutuzov MA (2004) Widespread presence of 'bacterial-like' PPP phosphatases in eukaryotes. BMC Evolutionary Biology 4, 47.

Arnold K, Bordoli L, Kopp J and Schwede T (2006) The SWISS-MODEL workspace: a web-based environment for protein structure homology modelling. Bioinformatics 22, 195-201.

Biasini M, Bienert S, Waterhouse A, Arnold K, Studer G, Schmidt T, Kiefer F, Gallo Cassarino T, Bertoni M, Bordoli L and Schwede T (2014) SWISS-MODEL: modelling protein tertiary and quaternary structure using evolutionary information. Nucleic Acids Research 42, W252-W258.

Bordoli L, Kiefer F, Arnold K, Benkert P, Battey J and Schwede T (2009) Protein structure homology modeling using SWISS-MODEL workspace. Nature Protocols 4, 1-13.

Bradford MM (1976) A rapid and sensitive method for the quantitation of microgram quantities of protein utilizing the principle of protein-dye binding. Analytical Biochemistry 72, 248-254.

Brenchley R, Tariq H, McElhinney H, Szoor B, Huxley-Jones J, Stevens R, Matthews K and Tabernero L (2007) The TriTryp phosphatome: analysis of the protein phosphatase catalytic domains. BMC Genomics 8, 434.

Buchan DW, Minneci F, Nugent TC, Bryson K and Jones DT (2013) Scalable web services for the PSIPRED Protein Analysis Workbench. Nucleic Acids Research 41, W349-W357.

Burns JM Jr, Parsons M, Rosman DE and Reed SG (1993) Molecular cloning and characterization of a $42-\mathrm{kDa}$ protein phosphatase of Leishmania chagasi. The Journal of Biological Chemistry 268, 17155-17161.

Cohen P (2002) The origins of protein phosphorylation. Nature Cell Biology 4 E127-E130.

Das AK, Helps NR, Cohen PT and Barford D (1996) Crystal structure of the protein serine/threonine phosphatase $2 \mathrm{C}$ at $2.0 \mathrm{~A}$ resolution. The $E M B O$ Journal. 15, 6798-6809.

Dissing J, Dahl O and Svensmark O (1979) Phosphonic and arsonic acids as inhibitors of human red cell acid phosphatase and their use in affinity chromatography. Biochimica et Biophys Acta 569, 159-176.

Gilbert LA, Ravindran S, Turetzky JM, Boothroyd JC and Bradley PJ (2007) Toxoplasma gondii targets a protein phosphatase $2 \mathrm{C}$ to the nuclei of infected host cells. Eukaryotic Cell 6, 73-83.

Gomez de Leon CT, Diaz Martin RD, Mendoza Hernandez G, Gonzalez Pozos S, Ambrosio JR and Mondragon Flores R (2014) Proteomic characterization of the subpellicular cytoskeleton of Toxoplasma gondii tachyzoites. Journal of Proteomics 111, 86-99.

Guex N, Peitsch MC and Schwede T (2009) Automated comparative protein structure modeling with SWISS-MODEL and Swiss-PdbViewer: a historical perspective. Electrophoresis 30 (Suppl. 1), S162-S173.

Ivens AC, Peacock CS, Worthey EA, Murphy L, Aggarwal G, Berriman M, Sisk E, Rajandream MA, Adlem E, Aert R, Anupama A, Apostolou Z, Attipoe P, Bason N, Bauser C, Beck A, Beverley SM, Bianchettin G, Borzym K, Bothe G, Bruschi CV, Collins M, Cadag E, Ciarloni L, Clayton C, Coulson RM, Cronin A, Cruz AK, Davies RM, De Gaudenzi J, Dobson DE, Duesterhoeft A, Fazelina G, Fosker N, Frasch AC, Fraser A, Fuchs M, Gabel C, Goble A, Goffeau A, Harris D, Hertz-Fowler C, Hilbert H, Horn D, Huang Y, Klages S, Knights A, Kube M, Larke N, Litvin L, Lord A, Louie T, Marra M, Masuy D, Matthews K, Michaeli S, Mottram JC, Muller-Auer S, Munden H, Nelson S, Norbertczak H, Oliver K, O’Neil S, Pentony M, Pohl TM, Price C, Purnelle B, Quail MA, Rabbinowitsch E, Reinhardt R, Rieger M, Rinta J, Robben J, Robertson L, Ruiz JC, Rutter S, Saunders D, Schafer M, Schein J, Schwartz DC, Seeger K, Seyler A, Sharp S, Shin H, Sivam D, Squares R, Squares S, Tosato V, Vogt C, Volckaert G, Wambutt R, Warren T, Wedler H, Woodward J, Zhou S, Zimmermann W, Smith DF, Blackwell JM, Stuart KD, Barrell B and Myler PJ (2005) The genome of the kinetoplastid parasite, Leishmania major. Science 309, 436-442.
Kennelly PJ (2001) Protein phosphatases - a phylogenetic perspective. Chemical Reviews 101, 2291-2312.

Kumar KA, Garcia CR, Chandran VR, Van Rooijen N, Zhou Y, Winzeler E and Nussenzweig V (2007) Exposure of plasmodium sporozoites to the intracellular concentration of potassium enhances infectivity and reduces cell passage activity. Molecular and Biochemical Parasitology 156, 32-40.

Lammers T and Lavi S (2007) Role of type 2C protein phosphatases in growth regulation and in cellular stress signaling. Critical Reviews in Biochemistry and Molecular Biology 42, 437-461.

Mamoun CB, Sullivan DJ Jr, Banerjee R and Goldberg DE (1998) Identification and characterization of an unusual double serine/threonine protein phosphatase $2 \mathrm{C}$ in the malaria parasite Plasmodium falciparum. The Journal of Biological Chemistry 273, 11241-11247.

Melo F, Sanchez R and Sali A (2002) Statistical potentials for fold assessment. Protein Science: a Publication of the Protein Society 11, 430-448.

Mitula F, Tajdel M, Ciesla A, Kasprowicz-Maluski A, Kulik A, Babula-Skowronska D, Michalak M, Dobrowolska G, Sadowski J and Ludwikow A (2015) Arabidopsis ABA-activated kinase MAPKKK18 is regulated by protein phosphatase $2 \mathrm{C} \mathrm{ABI1}$ and the ubiquitin-proteasome pathway. Plant \& Cell Physiology 56, 2351-2367.

Montfort I, Perez-Tamayo R, Perez-Montfort R, Gonzalez Canto A and Olivos A (1994) Purification and immunologic characterization of a $30-\mathrm{kDa}$ cysteine proteinase of Entamoeba histolytica. Parasitology Research 80, 607-613.

Moorhead GB, Trinkle-Mulcahy L and Ulke-Lemee A (2007) Emerging roles of nuclear protein phosphatases. Nature Reviews Molecular Cell Biology 8, 234-244.

Mukhopadhyay S, Kapatral V, Xu W and Chakrabarty AM (1999) Characterization of a Hank's type serine/threonine kinase and serine/threonine phosphoprotein phosphatase in Pseudomonas aeruginosa. Journal of Bacteriology 181, 6615-6622.

Obuchowski M, Madec E, Delattre D, Boel G, Iwanicki A, Foulger D and Seror SJ (2000) Characterization of PrpC from Bacillus subtilis, a member of the PPM phosphatase family. Journal of Bacteriology 182, 5634-5638.

Prestes EB, Bayer-Santos E, Hermes Stoco P, Sincero TC, Wagner G, Umaki A, Fragoso SP, Bordignon J, Steindel M and Grisard EC (2012) Trypanosoma rangeli protein tyrosine phosphatase is associated with the parasite's flagellum. Memorias do Instituto Oswaldo Cruz 107, 713-719.

Pullen KE, Ng HL, Sung PY, Good MC, Smith SM and Alber T (2004) An alternate conformation and a third metal in PstP/Ppp, the M. tuberculosis PP2C-family Ser/Thr protein phosphatase. Structure 12, 1947-1954.

Rajagopal L, Clancy A and Rubens CE (2003) A eukaryotic type serine/threonine kinase and phosphatase in Streptococcus agalactiae reversibly phosphorylate an inorganic pyrophosphatase and affect growth, cell segregation, and virulence. The Journal of Biological Chemistry 278, 14429-14441.

Ruppert U, Irmler A, Kloft N and Forchhammer K (2002) The novel protein phosphatase PphA from synechocystis PCC 6803 controls dephosphorylation of the signalling protein PII. Molecular Microbiology 44, 855-864.

Schlicker C, Fokina O, Kloft N, Grune T, Becker S, Sheldrick GM and Forchhammer K (2008) Structural analysis of the PP2C phosphatase tPphA from Thermosynechococcus elongatus: a flexible flap subdomain controls access to the catalytic site. Journal of Molecular Biology 376, 570-581.

Schweighofer A, Hirt $\mathbf{H}$ and Meskiene I (2004) Plant PP2C phosphatases: emerging functions in stress signaling. Trends Plant Science 9, 236-243.

Shen MY and Sali A (2006) Statistical potential for assessment and prediction of protein structures. Protein Science: a Publication of the Protein Society $15,2507-2524$

Su J and Forchhammer K (2013) Determinants for substrate specificity of the bacterial PP2C protein phosphatase tPphA from Thermosynechococcus elongatus. The FEBS Journal 280, 694-707.

Su J, Schlicker C and Forchhammer K (2011) A third metal is required for catalytic activity of the signal-transducing protein phosphatase M tPphA. The Journal of Biological Chemistry 286, 13481-13488.

Wang B, Zhang P and Wei Q (2008) Recent progress on the structure of Ser/ Thr protein phosphatases. Science in China. Series C, Life Sciences/Chinese Academy of Sciences 51, 487-494. 